\title{
Boosting the supercapacitive behavior of CoAl-layered double hydroxides via tuning the metal composition and interlayer space
}

\author{
Alvaro Seijas-Da Silva ${ }^{\ddagger}$, Roger Sanchis-Gual ${ }^{\ddagger}$, Jose A. Carrasco ${ }^{\ddagger}$, Víctor Oestreicher, Gonzalo \\ Abellán* and Eugenio Coronado
}

¥These authors contributed equally to this work.

\begin{abstract}
Layered double hydroxides (LDHs) are promising supercapacitor materials due to their wide chemical versatility, earth abundant metals and high specific capacitances. Many parameters influencing the supercapacitive performance have been studied such as the chemical composition, the synthetic approaches, and the interlayer anion. However, no systematic studies about the effect of the basal space have been carried out. Here, two-dimensional (2D) CoAl-LDHs were synthesized through anion exchange reactions using surfactant molecules in order to increase the interlayer space (ranging from 7.5 to 32.0 $\AA$ ). These compounds exhibit similar size and dimensions but different basal space to explore exclusively the interlayer distance influence in the supercapacitive performance. In this line, Co:Al ratios of 2:1, 3:1 and 4:1 were explored. In all cases, an enhancement of the specific capacitance was observed by increasing the basal space, reaching ca. $50 \%$ more than the value obtained from the less-spaced 2:1 CoAl-LDH (up to ca. 750 - 1100 F.g-1 at 1 A.g-1). This increment mainly occurs because of the increase in the electrochemical surface area (up to ca. $260 \%$ ) and the higher electrolyte diffusion. Interestingly, best performance is achieved for the lowest Co:Al ratio (i. e. the highest $\mathrm{Al}$ content) revealing the important role of the electrochemically inert $\mathrm{Al}$ in the structure.
\end{abstract}

\section{Introduction}

In view of the current energy and environmental problems, the energy storage field is attracting widespread attention due to the possibility of using of electricity coming from renewable sources. Energy storage systems include capacitors, supercapacitors, batteries and fuel cells. ${ }^{[1,2]}$ Regarding the supercapacitors, they present a high-power storage ability in combination with fast discharge cycles, making them ideal in temporary energy storage applications, among others. ${ }^{[3]}$ Nowadays, the current supercapacitors are classified in electrochemical double-layer supercapacitors (EDLC) based on carbon, pseudo-capacitors based on metal oxides or conducting polymers and hybrid

A. Seijas-Da Silva, R. Sanchis-Gual, Dr. J. A. Carrasco, Dr. V.

Oestreicher, Dr. G. Abellán and Prof. E. Coronado

Institute of Molecular Science, Universitat de València

Catedrático José Beltrán 2, 46980, Paterna, Spain

E-mail: Gonzalo.abellan@uv.es

Supporting information for this article is given via a link at the end of the document. capacitors based on mixtures of the above. Pseudo-capacitors and hybrid capacitors are both promising technologies thanks to their ability in achieving higher energy and power densities than the typical EDLC supercapacitors. ${ }^{[3]}$ In this context, layered materials have attracted increasing interest in these energy fields due to their excellent behavior towards energy storage systems. ${ }^{[4,5]}$ In particular, layered double hydroxides (LDHs) have been investigated for their potential application as electroactive materials due to their wide chemical tunability and electrochemical stability. ${ }^{[6,7]}$

LDHs are a class of anionic clays with exchangeable anions in the interlayer space composed of low-cost and earth-abundant transition metals. They exhibit a hydrotalcite-like structure with the typical formula $\left.\left[\mathrm{M}^{\prime \prime}{ }_{1-\chi} \mathrm{M}^{\prime \prime \prime}{ }_{\chi}(\mathrm{OH})_{2}\right]^{\chi^{+}}\left(\mathrm{A}^{\mathrm{n}-}\right)_{\chi / \mathrm{n}} \cdot \mathrm{mH}_{2} \mathrm{O}\right]$ where the relation between $\mathrm{M}^{\prime \prime}$ and $\mathrm{M}^{\text {III }}$ can be theoretically tuned (typically $0.20 \leq x \leq 0.33)$ and the interlayer anion $\left(\mathrm{A}^{\mathrm{n}-}\right)$ can be modified by anion exchange reactions resulting in a broad range of possibilities of both organic or inorganic molecules. ${ }^{[8]}$

Among the wide variety of possible metal compositions to give rise to an LDH phase, the best results reported in energy storage applications as supercapacitors are found for the Cobased ones. ${ }^{[6]}$ Furthermore, synthetic parameters like particle size, morphology, thickness and hybridization with conductive materials have been comprehensively studied in different LDHs with the aim of improving the electrochemical performance towards energy storage applications. ${ }^{[7,9-11]}$ Regarding the supercapacitive behavior, the intercalation of dodecyl sulfate allows an enhancement of $22 \%$ in the specific capacitance of a CoAl-LDH. ${ }^{[12]}$ In the same manner, the effect of space accessible to electrolyte ions on the electrochemical activity was studied for an $\mathrm{a}-\mathrm{Co}(\mathrm{OH})_{2}$ system. ${ }^{[13]}$ Nevertheless, only a few samples (3 materials exactly) were studied and compared in each case. Taking into account that the nature of the interlayer anion (i.e. size, hydrophobicity, acidity, etc) can influence the electrochemical properties, ${ }^{[14-16]}$ a systematic study exploring the supercapacitive performance with the progressive increasing of the basal space remains unexplored.

Consequently, in this work we thoroughly study a CoAl-LDH phase by keeping constant all synthetic parameters but varying the metallic ratio in order to gain deeper insights into its influence in the supercapacitive behavior. To obtain the LDH phase, a synthesis based on a homogeneous precipitation approach in the presence of urea was selected, as is reported to give rise to pure and well-defined LDH phases. ${ }^{[17]}$ In this sense, $\mathrm{Co}^{2+}: \mathrm{Al}^{3+}$ ratios of $2: 1,3: 1$ and $4: 1$ and a series of anion exchange reactions with surfactant molecules were carried out in order to increase the basal space of the LDH from $7.5 \AA$ to 32 $\AA$ hence enhancing the electroactive properties. Due to the fact that enlarging the interlayer space may have unexpected 
consequences, a complete electrochemical characterization has been carried out on all surfactant-intercalated intermediates. An increase of the supercapacitive performance was observed by expanding the basal space, exceeding in ca. $50 \%$ those capacitance values obtained from the pristine CoAl. This enhancement is related to the increase in the electrochemical surface area, improving the electrolyte diffusion in the interlayer gallery. It is important to remark that this noteworthy improvement was only achieved using a Co:Al ratio of 2:1. In fact, best specific capacitances were achieved for the lowest Co:Al ratio revealing the important role of the electrochemically inert $\mathrm{Al}$ in the structure. After the cycling stability tests, some Al is removed with a partial loss of the interlayer anion. This phenomenon is more evident in the most expanded LDH where the diffusion of electrolytes becomes higher.

\section{Results and Discussion}

All pristine CoAl-LDHs were initially synthesized via a modified homogeneous precipitation method in which the metallic chloride salts are combined in the desired ratio in the presence of urea giving rise to the final LDH phase. ${ }^{[17]}$ In this context, urea acts as an ammonium releasing reagent (ARR) with the aim of controlling the $\mathrm{pH}$ of the solution. Due to the choice of this synthetic approach, which leads to carbonate-intercalated LDHs, a subsequent two steps anion exchange reactions are mandatory for the purpose of this work. ${ }^{[18,19]}$ Furthermore, a well defined hexagonal morphology Co:Al ratio of 4:1 was synthesized for the first time using urea, in stark contrast with previous studies. ${ }^{[20]}$ It is worth pointing out that the preparation of some $\mathrm{LDHs}$ with a $\mathrm{M}^{2+}: \mathrm{M}^{3+}$ ratio higher than 3 requires a specific control of the precipitation $\mathrm{pH}$ avoiding the phase segregation. ${ }^{[21]}$ As reported in the literature, a metallic ratio between 2 and 3 is the most feasible for a CoAl-LDH by using ARR like urea, in contrast, higher ratios were obtained using traditional coprecipitation route, but observing a partial Cobalt oxidation for the highest ones. ${ }^{[2]}$ In order to increase the Co:Al ratio, a careful control of the $\mathrm{pH}$ in the final solution is crucial. While a slight excess of urea is enough to give rise to the $2: 1$ and $3: 1$ phase $(\mathrm{pH}$ of the solution after $48 \mathrm{~h}$ of ca. 8.9), a higher basicity is required for the $4: 1$ phase ( $\mathrm{pH}$ of $c a .9 .6$ and $0.105 \mathrm{M}$ of urea).
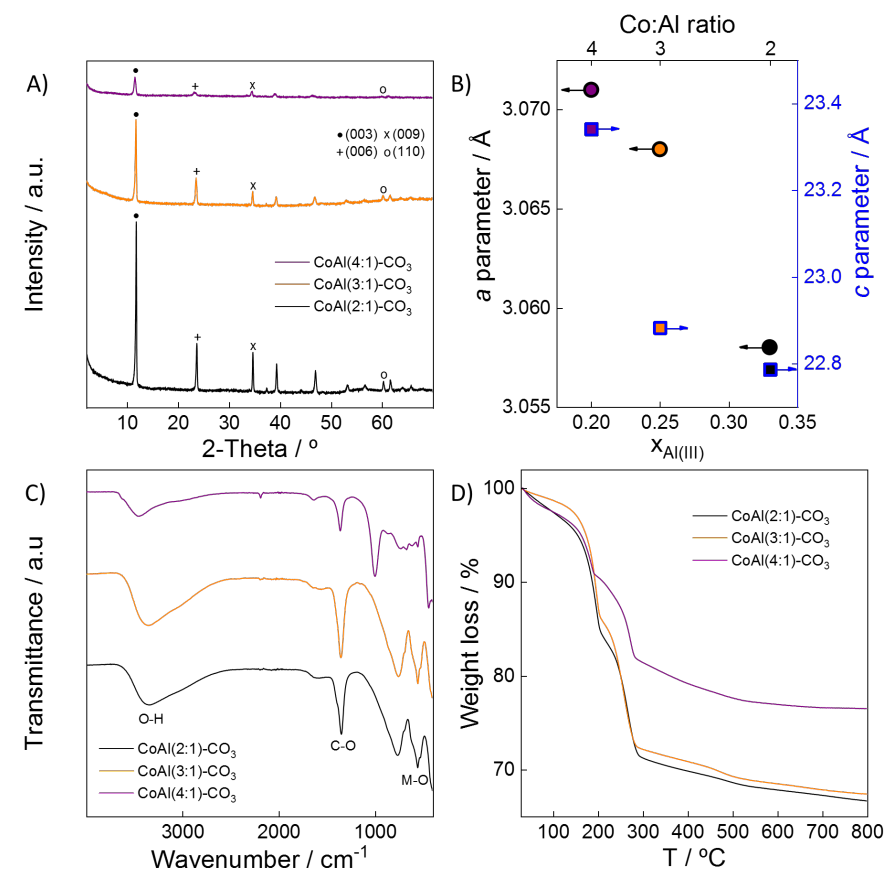

Figure 1. (A) XRPD, (B) Dependence of $a$ and $c$ parameters with the $\mathrm{XAl}_{\mathrm{Al}}(\mathrm{III})$ and the Co:Al ratio, (C) IR and (D) TG of the CoAl-LDHs synthesized with different ratios.

On the contrary, the Co:Al ratio is capped at a maximum of 3 (Figure S1). The successful synthesis of the CoAl-LDH phases were confirmed by X-ray powder diffraction (XRPD) (Figure 1A). All diffractograms exhibited the typical basal reflections expected for a hydrotalcite-like structure (JCPDS 22-700). ${ }^{[14,18]}$ In the light of the main (003), (006) and (009) basal reflections, a corresponding basal space of ca. $7.5 \AA$ can be calculated, related with the presence of $\mathrm{CO}_{3}{ }^{2-}$ as the interlayer anion, as expected. ${ }^{[17]}$ Basal spacing was estimated with the formula ( $\mathrm{d}_{003}$ $\left.+2 \cdot d_{006}+3 \cdot d_{009}\right) / 3$. In addition, the double peak centered at ca. $60^{\circ}$ is indicative of the intralayer distance M-O. ${ }^{[23,24]}$ Moreover, it is reported in the literature the strong correlation between both a and $c$ parameter of the unit cell of these layered structures $\left(d_{110}\right.$ and $\mathrm{d}_{003}$ ) with the $\mathrm{M}^{2+}: \mathrm{M}^{3+}$ ratio (or charge density). ${ }^{[24]}$ As observed in Figure 1B, the $a$ and $c$ value increases concomitantly with the metallic ratio in concordance with the replacement of a small cation $\left(\mathrm{Al}^{3+}\right)$ by a bigger one $\left(\mathrm{Co}^{2+}\right) \cdot{ }^{[25,26]}$ At the same time, the $c$ parameter presents the same trend, due to a decrease in the charge of the hydroxides layers. ${ }^{[27]}$ While 2:1 and 3:1 phases depict good crystallinity, the 4:1 phase does show a lower intensity in the peaks of the diffractogram. Attenuated total reflectance-Fourier transform infrared spectroscopy (ATR-FTIR) was also carried out to check the nature of the interlayer anion (Figure 1C). All samples exhibited the typical carbonate band at ca. $1350 \mathrm{~cm}^{-1}$, in combination with the broad band at ca. $3400 \mathrm{~cm}^{-1}$ and the peaks below $1000 \mathrm{~cm}^{-1}$, ascribed to the hydroxyl stretching vibrations and the metallic vibrational bands, respectively. ${ }^{[28,29]}$ Nevertheless, the ATR-FTIR 
spectrum of the $\mathrm{CoAl}(4: 1)-\mathrm{LDH}$ depicts some differences regarding the other compositions. Together with the expected decrease in the intensity of the carbonate band, there is the appearance of a band centred at ca. $1030 \mathrm{~cm}^{-1}$, possibly indicative of the presence of simple $\mathrm{Co}(\mathrm{OH})_{2}$ and $\mathrm{Al}(\mathrm{OH})_{3}$ in combination with an LDH phase. ${ }^{[30,31]}$ Since IR spectrum of $\mathrm{Co}(\mathrm{OH})_{2}$ matches with that expected for a CoAI-LDH, ${ }^{[17,30]}$ the band can be ascribed to a $\delta(\mathrm{OH})$ vibration mode of simple $\mathrm{Al}(\mathrm{OH})_{3}$ as reported in literature. ${ }^{[32]}$ Besides, $\mathrm{Al}(\mathrm{OH})_{3}$ can segregate as an amorphous phase, therefore being undetectable in XRPD. ${ }^{[30,33-35]}$ This hypothesis is also supported by the thermogravimetric analysis (TG) of the whole family. For a LDH phase, a typical TG profile is divided into three distinct regions. The first one consists of an initial weight loss in the 25$220{ }^{\circ} \mathrm{C}$ range, related with the elimination of the physisorbed solvent molecules (usually water) by the LDH structure. ${ }^{[36]}$ The following and most intense weight loss is the one observed in the $220-600{ }^{\circ} \mathrm{C}$ range, which is related with the overlapping of different processes such as the dehydroxylation and collapse of the layered system, the elimination of the chemisorbed water and of the interlayer anion. ${ }^{[37]}$ Finally, one can expect a last step above $600{ }^{\circ} \mathrm{C}$ where the crystallization of the resulting oxides occurs. ${ }^{[38]}$ Regarding our samples (Figure 1D), a total weight loss of 24,23 and $14 \%$ was found for the 2:1, 3:1 and 4:1 LDH phases, respectively. The low value obtained for the CoAl(4:1)LDH does not match with the expected for a carbonateintercalated $\mathrm{LDH}^{\left[{ }^{[39]}\right.}$ and supports the idea of a mixture of hydroxide phases. ${ }^{[30]}$ Regarding to the $\mathrm{Co}(\mathrm{OH})_{2}, \beta$-phase might be suggested according to the solid-state UV-Vis spectrum (Figure S2), where only octahedral coordinated Co" was observed (i.e. evidencing the absence of the $\alpha$-phase containing both $\mathrm{Co}(\mathrm{II})$ in octaedral and tetrahedral positions). ${ }^{[40,41]}$ Further evidences of a coexistence will be discussed in the magnetic characterization (vide infra).

The 2D morphology of the samples was unveiled by means of field emission scanning electron microscopy (FESEM). The assynthesized CoAl-LDHs exhibited well-defined hexagonal shapes (Figure 2), as expected for $\mathrm{Al}^{3+}$-containing LDHs. ${ }^{[18]}$ As long as the $\mathrm{Al}^{3+}$ content is decreased, the defined hexagonal morphology leads to a more circle-like form, with less-defined vertexes. Lateral dimensions were estimated by measuring a histogram of 50 particles, giving rise to average dimensions of ca. $6.2,5.1$ and $2.4 \mu \mathrm{m}$ for the 2:1, 3:1 and $4: 1$ ratio, respectively Additional low magnification SEM images can be found in Figure S3. While an average size in the 5-6 $\mu \mathrm{m}$ range is usually expected for CoAl-LDHs synthesized by a homogeneous precipitation method, ${ }^{[17-19]}$ the $4: 1$ phase exhibits smaller sizes. This fact is probably due to changes in the initial concentration of $\mathrm{Al}$, which affects the nucleation of the first $\mathrm{Al}(\mathrm{OH})_{3}$ seeds and hence the final size of the particle. ${ }^{[40,42]}$ Energy dispersive spectroscopy (EDX) measurements on the LDHs shows a successful experimental ratio of 2:1, 3:1 and 4:1 for the different samples (Table 1), and mapping analysis reveals a completely homogeneous distribution of both metals throughout the whole surface of the flakes (Figure S4), thus suggesting the in-plane coexistence of clustering-like phases instead of a physical mixture.

By combining elemental analysis, EDX and thermogravimetric analysis we can estimate the molecular formula of every
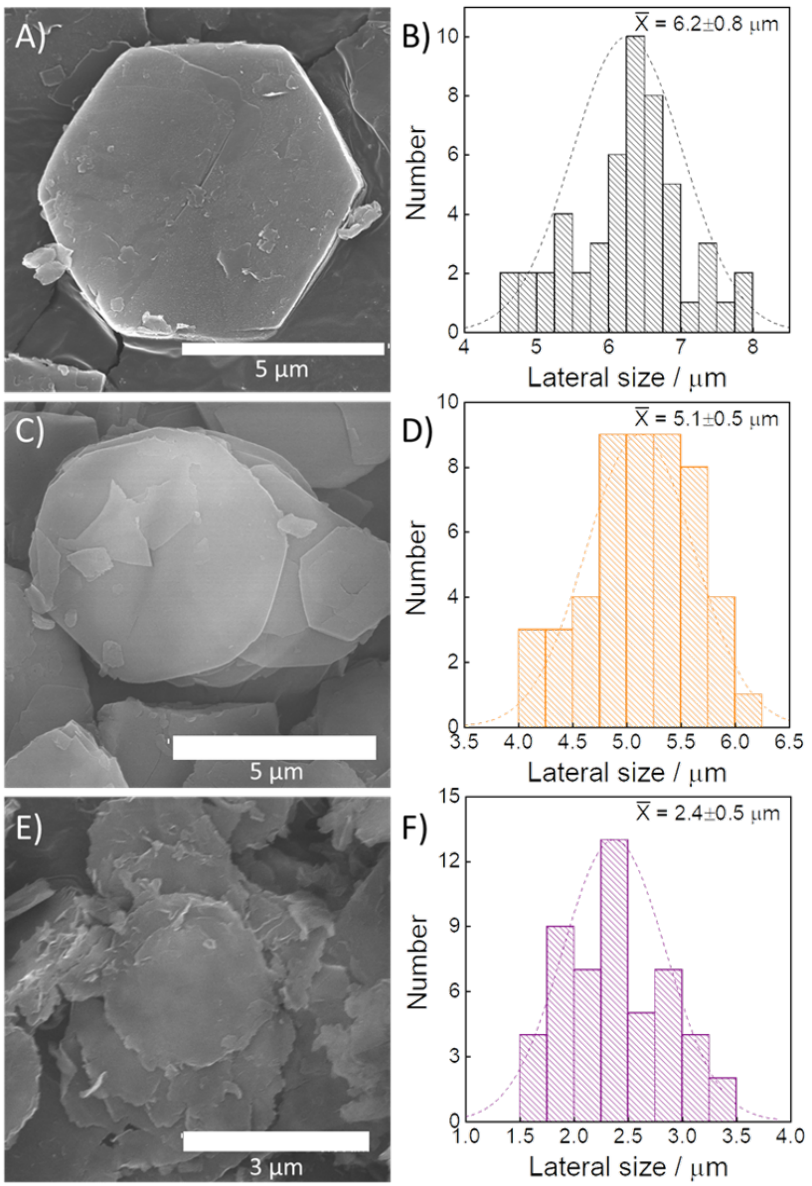

compound, crucial for the following electrochemical measurements (Table 1).

Figure 2. SEM images and particle size histograms highlighting the average lateral dimensions of $\mathrm{CoAl}_{-} \mathrm{CO}_{3}(\mathrm{~A}, \mathrm{~B}) 2: 1,(\mathrm{C}, \mathrm{D}) 3: 1$ ) and $(\mathrm{E}, \mathrm{F}) \mathrm{4:1}$

Table 1. Molecular formula, EDX ratio and elemental analysis of CoAl $2: 1,3: 1$ and $4: 1$

\begin{tabular}{cccc}
\hline \hline Molecular Formula & $\begin{array}{c}\text { Co:Al Ratio } \\
(\mathrm{EDX})\end{array}$ & $\mathrm{C}_{\text {found }}\left(\mathrm{C}_{\text {calc }}\right)$ & $\mathrm{H}_{\text {found }}\left(\mathrm{H}_{\text {calc }}\right)$ \\
\hline $\begin{array}{c}\mathrm{Co}_{0.64} \mathrm{Al}_{0.36}(\mathrm{OH})_{2} \\
\left(\mathrm{CO}_{3}\right)_{0.18} \cdot 1.00\left(\mathrm{H}_{2} \mathrm{O}\right)\end{array}$ & 1.77 & $1.90(1.96)$ & $3.34(3.65)$ \\
\hline $\begin{array}{c}\mathrm{Co}_{0.73} \mathrm{Al}_{0.27}(\mathrm{OH})_{2} \\
\left(\mathrm{CO}_{3}\right)_{0.135} \cdot 0.18\left(\mathrm{H}_{2} \mathrm{O}\right)\end{array}$ & 2.71 & $1.97(1.69)$ & $2.88(2.48)$ \\
\hline $\begin{array}{c}\mathrm{Co}_{0.79} \mathrm{Al}_{0.21}(\mathrm{OH})_{2} \\
\left(\mathrm{CO}_{3}\right)_{0.105} \cdot 0.30\left(\mathrm{H}_{2} \mathrm{O}\right)^{[a]}\end{array}$ & 3.80 & $1.32(1.28)$ & $2.66(2.67)$ \\
\hline
\end{tabular}

[a] Molecular formula estimated for the LDH phase of the $4: 1$ sample. 

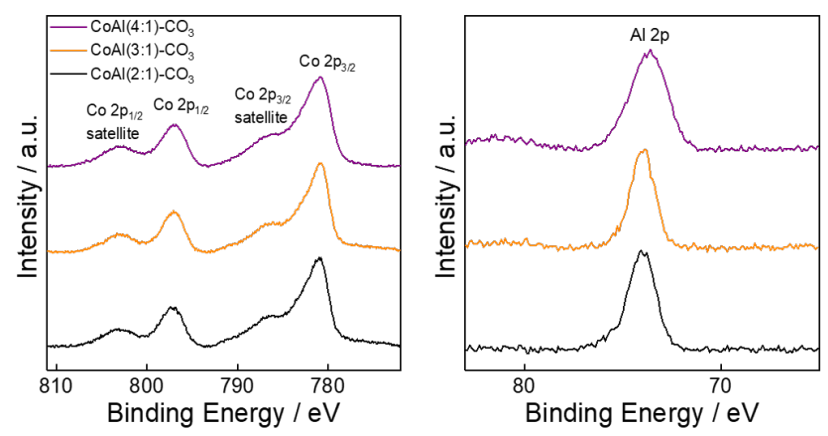

Figure 3. XPS spectra of the CoAI-LDHs with 2:1, 3:1 and 4:1 ratios.

Furthermore, X-ray photoelectron spectroscopy (XPS) analysis was carried out to corroborate the oxidation states of both Co and $\mathrm{Al}$ (Figure 3). The presence of $\mathrm{Co}(\mathrm{II})$ is demonstrated thanks to the appearance of the main Co $2 p_{3 / 2}$ and Co $2 p_{1 / 2}$ peaks at 781 and $798 \mathrm{eV}$, respectively, accompanied by their satellite peaks at 788 and $804 \mathrm{eV}$, as reported for single $\mathrm{Co}(\mathrm{OH})_{2}$ as well as CoAl-LDHs. ${ }^{[43-46]}$ In addition, the spectrum of $\mathrm{Al} 2 \mathrm{p}$ is expected to exhibit a single peak at $c a .74 \mathrm{eV}$. The observed peak is in good agreement with the reported signal for other CoAl-LDHs. ${ }^{[43,44]}$

Alongside with characterization techniques discussed, the purity of the samples was investigated by magnetic characterization, which also can reveal deeper insights into the possible segregated phases regarding the $4: 1$ sample. ${ }^{[14]}$ In this context, it is worth to mention that the overall magnetism in LDHs is controlled by two main contributions. On the one hand, the intralayer magnetic superexchange interactions between the neighboring metallic centers connected by hydroxo bridges (M$\mathrm{OH}-\mathrm{M})$. On the other hand, the interlayer and weaker dipolar interactions between the different LDH layers. ${ }^{[47]}$ Since LDHs only show magnetic behavior at low temperatures, the presence of a room-temperature contribution is reported to be caused by the presence of impurities in the form of Co oxides (spinels) that can be usually difficult to observe in the XRPD and need HRTEM measurements to be detected. ${ }^{[48,49]}$ Regarding the direct current measurements, Figure S5 (top line) plots the product of molar magnetic susceptibility times temperature $\chi \mathrm{M} \cdot \mathrm{T} v s$ to analyze the purity of the CoAl-LDHs. For all samples, there is a similar behaviour with no signal of magnetic contribution at room temperature and the presence of cooperative magnetic interactions at low temperatures. The peak at low temperature exhibits a sharp increase at ca. $50 \mathrm{~K}$, achieving a maximum value in the $4.0-4.5 \mathrm{emu} \cdot \mathrm{K} \cdot \mathrm{mol}^{-1}$ range at $5 \mathrm{~K}$ for the $\operatorname{CoAl}(2: 1)$ and $\mathrm{CoAl}(3: 1)-\mathrm{LDHs}$, and $16.0 \mathrm{emu} \cdot \mathrm{K} \cdot \mathrm{mol}^{-1}$ at $10 \mathrm{~K}$ for the CoAl(4:1)-LDH. In addition, the inverse of the magnetic susceptibility $\left(\chi_{\mathrm{M}}^{-1}\right)$ can be fitted to a Curie-Weiss lay in the hightemperature regime $(50-300 \mathrm{~K})$. All experimental Curie constants exhibit higher values than the theoretically calculated ones from the observed for spin-only contribution, due to the spin-orbit coupling of Co metals as previously reported. ${ }^{[18]}$ In line with this, the negative Weiss constants of all compounds are also indicative of the orbital contribution from octahedral Co(II). ${ }^{[18]}$ The hysteresis cycles recorded at $2 \mathrm{~K}$ for each compound (Figure S5, middle line) show coercive fields below 50 Oe for the $\operatorname{CoAl}(2: 1)$ and $\mathrm{CoAl}(3: 1)-\mathrm{LDH}$, i.e., soft magnets, and of ca. 1000 Oe for the CoAl(4:1)-LDH, i.e., hard magnet. These values match with the expected for pure CoAl-LDH $(2: 1$ and $3: 1$ ratios $)^{[18]}$ and the presence of a sort of a $\mathrm{Co}(\mathrm{OH})_{2}$ phase in the 4:1 ratio. ${ }^{[50-52]}$ Finally, alternate current measurements were recorded at different frequencies in order to check the dependence with the frequency of the magnetic signal (Figure $\mathrm{S} 5$, bottom line). The results confirm cooperative magnetism at low temperatures, with both in-phase ( $\left.\chi^{\prime} \mathrm{M}\right)$ and out-of-phase $\left(\chi{ }^{\prime \prime} M\right)$ signals exhibiting defined peaks with frequency dependence in the $1-1000 \mathrm{~Hz}$ range. From the $\chi$ "M signal it is possible to estimate the temperature for the onset spontaneous magnetization $\left(T_{M}\right)$, defined as the point where $\chi$ "M becomes non-equal to zero. While $\operatorname{CoAl}(2: 1)$ and $\operatorname{CoAl}(3: 1)-\mathrm{LDH}$ clearly
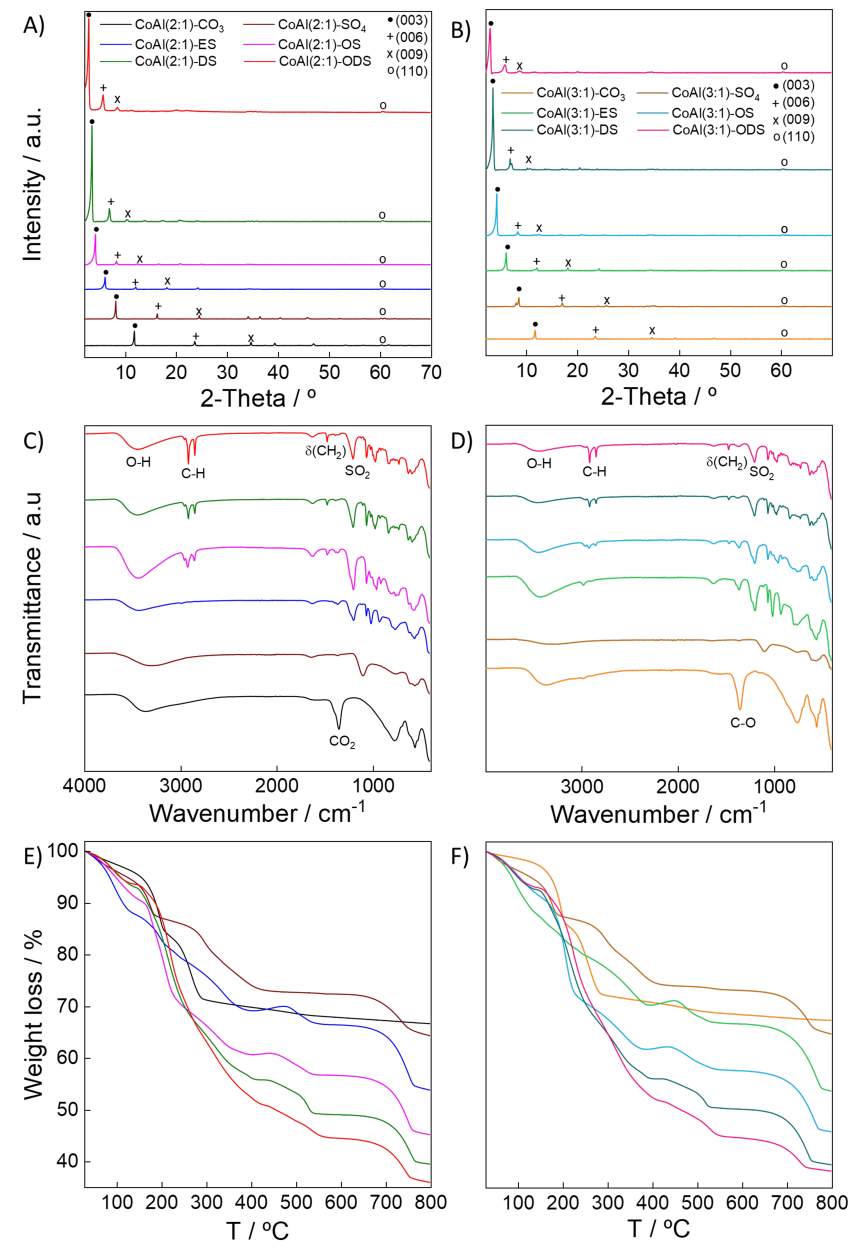
Figure 4. (A, B) XRPD, (C, D) IR and (E, F) TG of CoAlsurfactant intercalated LDHs with ratio 2:1 (left column) and 3:1 (right column)

present a single peak with a $\mathrm{T}_{\mathrm{M}}$ of $c a .4 \mathrm{~K}$ that matches with the calculated $T_{M}$ for other CoAl-LDHs ${ }^{[18,19,47]}$. The CoAl(4:1)-LDH depicts two new peaks at higher temperatures with maximum temperatures at ca. 16 and $7 \mathrm{~K}$, related with $2 \mathrm{D}$ short-range magnetic ordering and overall spontaneous magnetization mediated by interlayer antiferromagnetic dipolar interactions, respectively. A comparable behaviour has been previously reported for simple $\beta-\mathrm{Co}(\mathrm{OH})_{2}$ nanosheets. Thus confirming the coexistence of an in-plane clustering-like phase of a $\beta-\mathrm{Co}(\mathrm{OH})_{2}$

length of the interlayer anion. ${ }^{[18]}$ We observe that the basal peaks shift towards lower 2-Theta values as long as the length of the interlayer anion increases. At the same time, when the length of the interlayer surfactant rises, the intensity of basal peaks increases due to a greater ordering in the $c$ axis direction corresponding to a higher number of tail-to-tail interactions, which favours the stabilization of the system. ${ }^{[55,57,58]}$ The basal spaces reported for the surfactant-LDHs are ca. 11, 15, 22, 25 and $32 \AA$ for the CoAl-SO $4,-E S,-O S,-D S$ and -ODS, respectively. ${ }^{[14,18]}$. Regarding the IR spectra (Figure 4C,D), there are clear sulfate bands at ca. 1190 and $1050 \mathrm{~cm}^{-1}$ in combination with the $\mathrm{C}-\mathrm{H}$ stretching bands at ca. 2917 and $2845 \mathrm{~cm}^{-1}$ that are related with the hydrocarbon chain of the Table 2. Molecular formula and EDX ratio of the surfactant-intercalated CoAl-LDHs.

\begin{tabular}{|c|c|c|}
\hline Sample & Molecular Formula & Ratio Co:Al (EDX) \\
\hline $\mathrm{CoAl}(2: 1)-\mathrm{SO}_{4}$ & $\mathrm{Co}_{0.64} \mathrm{Al}_{0.36}(\mathrm{OH})_{2}\left(\mathrm{SO}_{4}\right)_{0.18} \cdot 1.4\left(\mathrm{H}_{2} \mathrm{O}\right)$ & 1.78 \\
\hline $\operatorname{CoAl}(2: 1)-E S$ & $\mathrm{Co}_{0.64} \mathrm{Al}_{0.36}(\mathrm{OH})_{2}\left(\mathrm{C}_{2} \mathrm{H}_{5} \mathrm{O}_{4} \mathrm{~S}\right)_{0.34}\left(\mathrm{NO}_{3}\right)_{0.02} \cdot 2.0\left(\mathrm{H}_{2} \mathrm{O}\right)$ & 1.80 \\
\hline CoAl(2:1)-OS & $\mathrm{Co}_{0.64} \mathrm{Al}_{0.36}(\mathrm{OH})_{2}\left(\mathrm{C}_{8} \mathrm{H}_{17} \mathrm{O}_{4} \mathrm{~S}\right)_{0.36} \cdot 2.0\left(\mathrm{H}_{2} \mathrm{O}\right)$ & 1.80 \\
\hline $\operatorname{CoAl}(2: 1)-D S$ & $\mathrm{Co}_{0.65} \mathrm{Al}_{0.35}(\mathrm{OH})_{2}\left(\mathrm{C}_{12} \mathrm{H}_{25} \mathrm{O}_{4} \mathrm{~S}\right)_{0.35} \cdot 1.4\left(\mathrm{H}_{2} \mathrm{O}\right)$ & 1.85 \\
\hline COAI(2:1)-ODS & $\mathrm{Co}_{0.65} \mathrm{Al}_{0.35}(\mathrm{OH})_{2}\left(\mathrm{C}_{18} \mathrm{H}_{37} \mathrm{O}_{4} \mathrm{~S}\right)_{0.32}\left(\mathrm{NO}_{3}\right)_{0.03} \cdot 1.5\left(\mathrm{H}_{2} \mathrm{O}\right)$ & 1.87 \\
\hline $\mathrm{CoAl}(3: 1)-\mathrm{SO}_{4}$ & $\mathrm{Co}_{0.73} \mathrm{Al}_{0.27}(\mathrm{OH})_{2}\left(\mathrm{SO}_{4}\right)_{0.135} \cdot 0.64\left(\mathrm{H}_{2} \mathrm{O}\right) \cdot 0.02\left(\mathrm{C}_{2} \mathrm{H}_{5} \mathrm{OH}\right)$ & 2.80 \\
\hline $\operatorname{CoA} /(3: 1)-E S$ & $\mathrm{Co}_{0.74} \mathrm{Al}_{0.26}(\mathrm{OH})_{2}\left(\mathrm{C}_{2} \mathrm{H}_{5} \mathrm{O}_{4} \mathrm{~S}_{0.26} \cdot 0.7\left(\mathrm{H}_{2} \mathrm{O}\right)\right.$ & 2.81 \\
\hline COAl(3:1)-OS & $\mathrm{Co}_{0.75} \mathrm{Al}_{0.25}(\mathrm{OH})_{2}\left(\mathrm{C}_{8} \mathrm{H}_{17} \mathrm{O}_{4} \mathrm{~S}\right)_{0.25} \cdot 0.45\left(\mathrm{H}_{2} \mathrm{O}\right)$ & 2.93 \\
\hline CoAl(3:1)-DS & $\mathrm{Co}_{0.73} \mathrm{Al}_{0.27}(\mathrm{OH})_{2}\left(\mathrm{C}_{12} \mathrm{H}_{25} \mathrm{O}_{4} \mathrm{~S}\right)_{0.27} \cdot 0.32\left(\mathrm{H}_{2} \mathrm{O}\right) \cdot 0.08\left(\mathrm{C}_{2} \mathrm{H}_{5} \mathrm{OH}\right)$ & 2.70 \\
\hline COAl(3:1)-ODS & $\mathrm{Co}_{0.73} \mathrm{Al}_{0.27}(\mathrm{OH})_{2}\left(\mathrm{C}_{18} \mathrm{H}_{37} \mathrm{O}_{4} \mathrm{~S}\right)_{0.27} \cdot 0.6\left(\mathrm{H}_{2} \mathrm{O}\right)$ & 2.73 \\
\hline
\end{tabular}

and a CoAI-LDH with a ratio lower than $4: 1 .{ }^{[53]}$ All magnetic data can be found in Table S1.

Since the CoAl(4:1)-LDH exhibits a complex structure with some phase-segregation, we feel unnatural to compare its electrochemical behaviour with that of a conventional LDH phase. Henceforth, we only address the electrochemical comparison between $\operatorname{CoAl}(2: 1)$ and $\operatorname{CoAl}(3: 1)-$ LDHs.

Prior to the electrochemical characterization, and taken into account the most recent papers about the enhancement of the electrochemical performance of the NiFe-LDHs after the enlargement of the interlayer space, ${ }^{[54,14]}$ a series of anionexchange reactions were carried out on the pristine phases.

In this sense, the pure $\operatorname{CoAl}(2: 1)$ and $\operatorname{CoAl}(3: 1)-\mathrm{LDHs}$ were selected to obtain a complete family of surfactant-intercalated samples, ranging from a basal spacing of ca. $7.5 \AA$ (with $\mathrm{CO}_{3}{ }^{2-}$ as the interlayer anion) to ca. $32 \AA$ (with octadecyl sulfate in the interlayer space). Before the insertion of the surfactant moieties, the pristine $\mathrm{CoAl}-\mathrm{CO}_{3} \mathrm{LDHs}$ was exchanged to a $\mathrm{CoAl}-\mathrm{NO}_{3}$ form because of the ease in replacing nitrate for other monovalent anions. ${ }^{[18,55,56]}$ Afterwards, a family of $n$-alkyl sulfates with increasing number of carbons were exchanged: $\mathrm{SO}_{4}{ }^{2-}, \mathrm{ES}^{-}$ (ethyl sulfate), OS $^{-}$(octyl sulfate), DS- (dodecyl sulfate) and ODS $^{-}$(octadecyl sulfate), with $0,2,8,12$ and 18 carbon atoms, respectively. The synthetic conditions for each surfactant were selected based on previously optimized anion exchange reactions reported bibliography in order to ensure the successful anion exchange reactions. ${ }^{[14,18]}$ Figure 4 highlights the physical characterization of all surfactant-intercalated samples. The recorded diffractograms (Figure $4 \mathrm{~A}, \mathrm{~B}$ ) point out the main basal reflections (003), (006) and (009), whose position is related to the basal spacing of the $\mathrm{LDH}$, and therefore dependent with the surfactants. ${ }^{[59]}$ The $\mathrm{C}-\mathrm{H}$ bands depict an enhancement of their intensity as long as the length of the surfactant increases. Remarkably, the $\mathrm{SO}_{2}$ band appears at ca. $1219 \mathrm{~cm}^{-1}$ for the surfactant-intercalated samples, and at ca. $1100 \mathrm{~cm}^{-1}$ for the $\mathrm{CoAl}-\mathrm{SO}_{4}$. This matches with that previously reported in the literature due to the loss of interaction between the headgroup and the carboxylic chain. ${ }^{[59,60]}$

Furthermore, the successful intercalation of the surfactant moieties was confirmed through TGA measurements (Figure $4 \mathrm{E}, \mathrm{F})$, pointing out a higher weight loss as the size of the molecules increases, as expected. ${ }^{[14,18]}$ In addition, the weight losses at ca. $500{ }^{\circ} \mathrm{C}$ and $700{ }^{\circ} \mathrm{C}$ correspond mainly to the decomposition of the aliphatic chains of the surfactants and the sulfate moieties, respectively (Figure S6).

Moreover, anion exchange reactions do not affect the overall morphology, and all the intercalated-LDHs preserve the pristine hexagonal shapes as well as the desired metallic ratio. Figures S7 and S8 depict FESEM images meanwhile Table 2 shows the estimated molecular formula for both $\operatorname{CoAl}(2: 1)$ and $\operatorname{CoAl}(3: 1)-$ surfactant LDHs based on elemental analysis (Table S2), TG and EDX. With respect to the $\mathrm{CoAl}(4: 1)$ sample, we have carried out an anion exchange reaction with the largest basal space studied, i.e., the ODS molecule. Figure S9 highlights the favourable insertion of the anion in the interlayer space thanks to the XRPD, IR and TG data, further supporting the in-plane coexistence of CoAl-LDH and $\beta$-Co hydroxide. 
A)

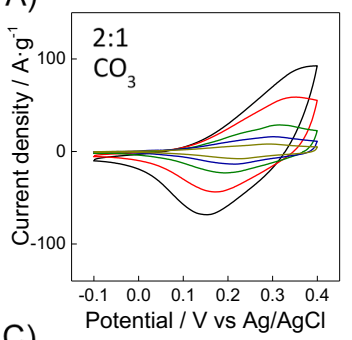

B)

C)

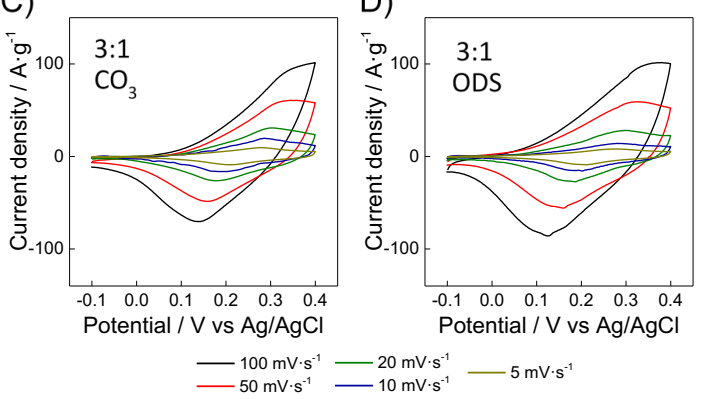

Figure 5. Cyclic voltammetry curves at different scan rates of the most distanced samples using different Co:Al ratios. Current density was obtained considering the total metal hydroxide mass.

The electrochemical performance of the as-synthesized and intercalated-LDHs was tested in order to understand how the energy storage capabilities can be influenced by the interlayer distance. To study properly this influence for each sample, metal hydroxide mass was kept constant, since the high capacitance of these materials comes from the Faradaic reactions of these species. ${ }^{[61]}$ In this sense, it is well-known that Faradaic reaction occurs on the interface between the electrolyte and active electrode materials. Consequently, an appropriate space to allow the electrolyte to access and diffuse is required. ${ }^{[62]}$ This effect should be specially pronounced comparing the most distanced samples. To do so, cyclic voltammetry (CV) curves for the least and the most spaced LDHs were performed to ascertain the presence of the $\mathrm{Co}(\mathrm{OH})_{2}$ redox processes and to evaluate possible differences in the current density of those peaks (Figure 5 and Figure S10). In all cases, these peaks are observable between $0.1-0.4 \mathrm{~V}$, as reported elsewhere ${ }^{[63,64]} \mathrm{As}$ it can be observed from $\mathrm{CV}$, the current density increases upon the enlargement of the basal space. Surprisingly, this increase is clearly noticeable for the CoAl(2:1)-LDH but it is not so evident for higher Co ratios. In fact, the current density increase can be followed upon the progressive enlargement of the interlayer distance for the $\operatorname{CoAl}(2: 1)$ family (Figure S11). Also, it is important to remark that $\mathrm{CoAl}(4: 1)-\mathrm{LDHs}$ display low current density reliably because of the inexistence of a single pure LDH phase (Figure S12). Figure 6A presents the specific capacitance calculated from the discharge curves for the least and most spaced for the three CoAl-LDH compositions. All discharge curves are available in Figure S14. For the $\operatorname{CoAl}(2: 1)-L D H s$, it was observed an increment of the specific capacitance, going from ca. $750 \mathrm{~F} \cdot \mathrm{g}^{-1}$ and $500 \mathrm{~F} \cdot \mathrm{g}^{-1}$ (at 1 and $30 \mathrm{~A} \cdot \mathrm{g}^{-1}$, respectively) for the $\mathrm{CoAl}(2: 1)-\mathrm{CO}_{3}$ to ca. 1100 and $750 \mathrm{~F} \cdot \mathrm{g}^{-1}$ (at 1 and 30 $A \cdot g^{-1}$, respectively) for the $\operatorname{CoAl}(2: 1)-O D S$. This enhancement supposes an increment in the specific capacitance of around $50 \%$. The enhancement of the capacitance values was also experimentally detected for both the CoAI(3:1)-LDHs and the CoAl(4:1)-LDHs. Indeed, the specific capacitance improves by $14 \%$ and $42 \%$ at 1 and $30 \mathrm{~A} \cdot \mathrm{g}^{-1}$, respectively, for the CoAl(3:1)-LDHs. In addition, the improvement for the CoAl(4:1)$\mathrm{LDHs}$ is about $15 \%$ and $3 \%$ at 1 and $30 \mathrm{~A} \cdot \mathrm{g}^{-1}$, respectively (Figure S13). Thus, the enhancements found in the three compositions suggest a connection between the specific capacitance and the basal space. For this reason, a detailed study was carried out for the whole family of CoAl(2:1)-LDH. Figure $6 \mathrm{~B}$ shows the specific capacitance calculated from the discharge curves. In general, a clear tendency was observed where the specific capacitance increases concomitantly with the basal space. Another issue to comment is the decrease in the specific capacitance when increasing the Co:Al ratio. This can be correlated to the introduction of $\mathrm{Al}$ in the mixed metal hydroxide layers, which greatly improves the electrochemical activity of reversible reactions such as $\mathrm{Co}^{2+} \cdot{ }^{[65]}$ In fact, Al favours the retention of the original layered structure during the redox reaction since it does not involve any change of valence during the charge/discharge process. On the other hand, its partial dissolution generates more active sites for Faradic redox reactions and improves the diffusion of the electrolyte through the electroactive sites. ${ }^{[6,66,67]}$ In this line, the specific capacitance for the $\beta-\mathrm{Co}(\mathrm{OH})_{2}$ (thus, without inert species) is even inferior (Figure $6 \mathrm{C}$ and $\mathrm{S} 15$ ) revealing the importance of the total accessible electroactive sites over the total amount of electroactive mass. Thereby, these results suggest that the partial Al dissolution plays a crucial role and overcome the increasing of the Co:Al ratio (i.e. of hydroxide species). In the Supporting Information (Table S3, S4 and S5), it can be found the specific capacitances calculated in $\mathrm{mA} \cdot \mathrm{h} \cdot \mathrm{g}^{-1}$ because of the potential application of CoAl-LDH as additive for cathodes in batteries. ${ }^{[68]}$ 


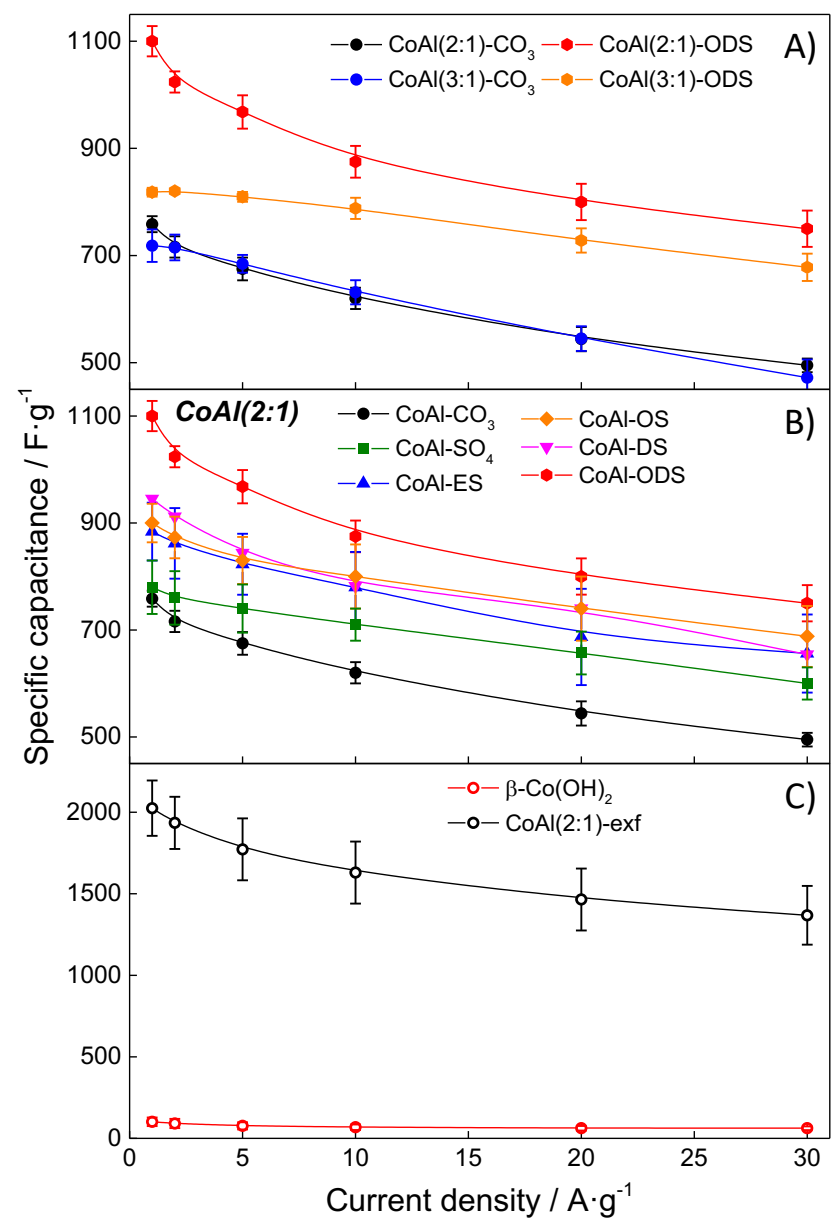

Figure 6. Specific capacitance of: the most distanced CoAl-LDHs using different metal ratio $(\mathrm{A})$, the whole family of $\mathrm{CoAl}(2: 1)-\mathrm{LDH}$ and $\mathrm{C}$ ) the $\beta$ $\mathrm{Co}(\mathrm{OH})_{2}$ and the exfoliated $\mathrm{CoAl}(2: 1)$. The specific capacitance values were obtained by subjecting the material at different current densities $(30,20,10,5$, 2 and $\left.1 \mathrm{~A} \cdot \mathrm{g}^{-1}\right)$. Current densities were applied considering the total metal hydroxide mass.

To further deepen the observed electrochemical results, we extracted the electrochemical surface area (ECSA) of all the CoAI(2:1)-LDH family. In general, a large ECSA is favourable for the exposure of the active sites. Related to this, it is wellknown that an increase in the specific surface area and, thus, in the number of electroactive sites, leads to an improvement of electrochemical performance. ${ }^{[69]}$ The ECSA values were calculated from $\mathrm{CV}$ curves measured in a non-Faradaic region at different scan rates (Figure 7A,C). The slopes of the fitted plots correspond to twice of the double-layer capacitance. As shown in Figure 7B, ECSA improves near the $260 \%$ its value by enlarging the basal space using the $\operatorname{CoAl}(2: 1)$ composition (see Figure $7 C, D$ ). However, it is important to remark that there is a reduction of the ECSA with the increase of the Co:Al ratio (Figure S17), being this tendency even more evident for CoAlODS samples. This decrease of the ECSA values is in good agreement with the specific capacitances observed in Figure $6 \mathrm{~A}$ indicating that the presence of larger electroactive sites is a key factor in order to boost the electrochemical performance. In fact,
ECSA increases by progressive enlarging the interlayer distance following a similar trend to the aforementioned specific capacitance values (see Figure $6 B$ and 7D) indictating the increment of the accessible electroactive sites. In this manner, the ECSA of the exfoliated $\operatorname{CoAl}(2: 1)$ in formamide, which represents the limit case, is the highest (around $2.6 \mathrm{mF} \cdot \mathrm{g}^{-1}$ ) as it is expected due to the presence of more electroactive sites. This fact is clearly reflected in the specific capacitance exhibiting an excellent performance of $2100 \mathrm{~F} \cdot \mathrm{g}^{-1}$ at $1 \mathrm{Ag}^{-1}$ (see Figure $6 \mathrm{C}$ and S16). ${ }^{[70]}$
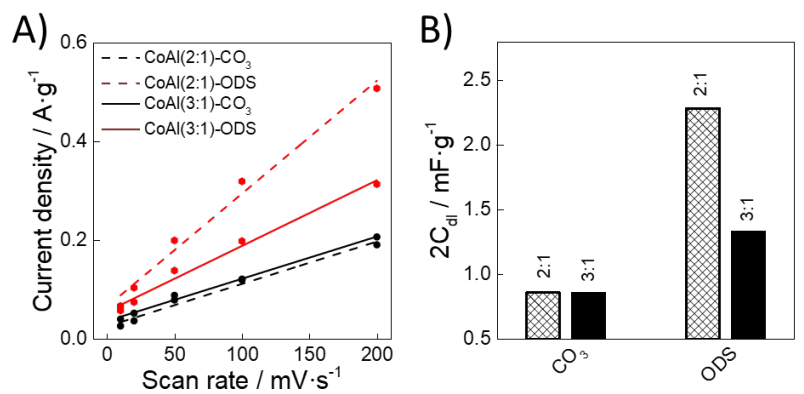

C)

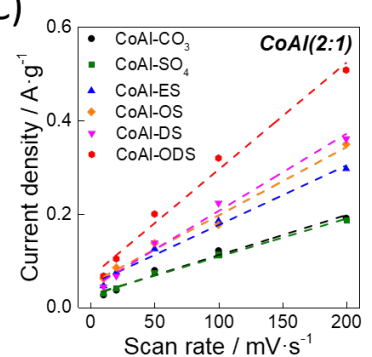

D)

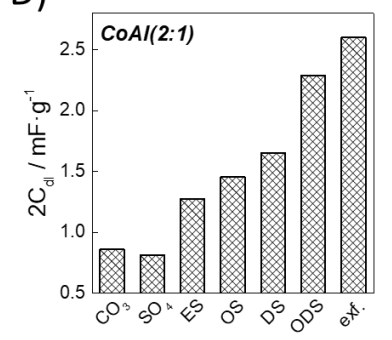

Figure 7. A) Linear slope values representing the ECSA of the $\mathrm{CoAl}-\mathrm{CO}_{3}$ and CoAl-ODS samples calculated from CVs performed in a non-faradaic region at different scan rates. B) ECSA values extracted from Figure 7A. C) Linear slope values representing the ECSA of the $\operatorname{CoAl}(2: 1)$ family calculated from CVs performed in a non-faradaic region at different scan rates. D) ECSA values extracted from Figure $7 \mathrm{C}$.

To investigate the processes occurring in the electrode, electrochemical impedance spectroscopy (EIS) was carried out. Figure S18A shows Nyquist plots displayed from the CoAl-ODS of different metal compositions and Figure S18B the measurements obtained from the whole CoAI(2:1)-LDH family. The equivalent circuit used to fit all these data is shown in Figure $\mathrm{S} 18 \mathrm{C}$. This model is composed of two resistances, corresponding to the solution and the charge transfer, and a double charge capacitance in the high-frequency region. On the other hand, in the low-frequency region, diffusion processes and pseudocapacitance are represented by a Warburg and a constant phase element. In Figure S18B it can be noticed that the slope located at low frequencies becomes slightly more vertical as the basal space is greater, indicating higher electrolyte mobility due to the broader interlayer space. In the same way, the reduction of the Co:Al ratio leads to a steeper slope and, thus, to higher electrolyte accessibility. Thus, the improvement of the capacitor-like behaviour is related to the accessibility of the electrolyte to the electroactive species. This 
effect can be achieved by enlarging the basal space but also by decreasing the Co:Al ratio (Figure S18A).

Cycling stability is fundamental for its application in practical devices. Hence, 10000 charge/discharge cycles were performed to evaluate the most spaced $\mathrm{CoAI}(2: 1)-\mathrm{LDHs}$. In Figure 8A, it can be appreciated the stability of both samples. Remarkably, the capacitance rapidly decreases in the CoAl-ODS during the 2000 first cycles and subsequently, the material preserves similar capacitance retention (around $50 \%$ ). The $\mathrm{CoAl}-\mathrm{CO}_{3}$ exhibits different tendencies but reaching the same point, with around $50 \%$ of capacitance retention. Nevertheless, the diminution of its capacitance appears to be slower. Possibly, the easier accessibility of the electrolyte into the electroactive sites leads to a more facile dissolution of the Al. ${ }^{[65,67]}$
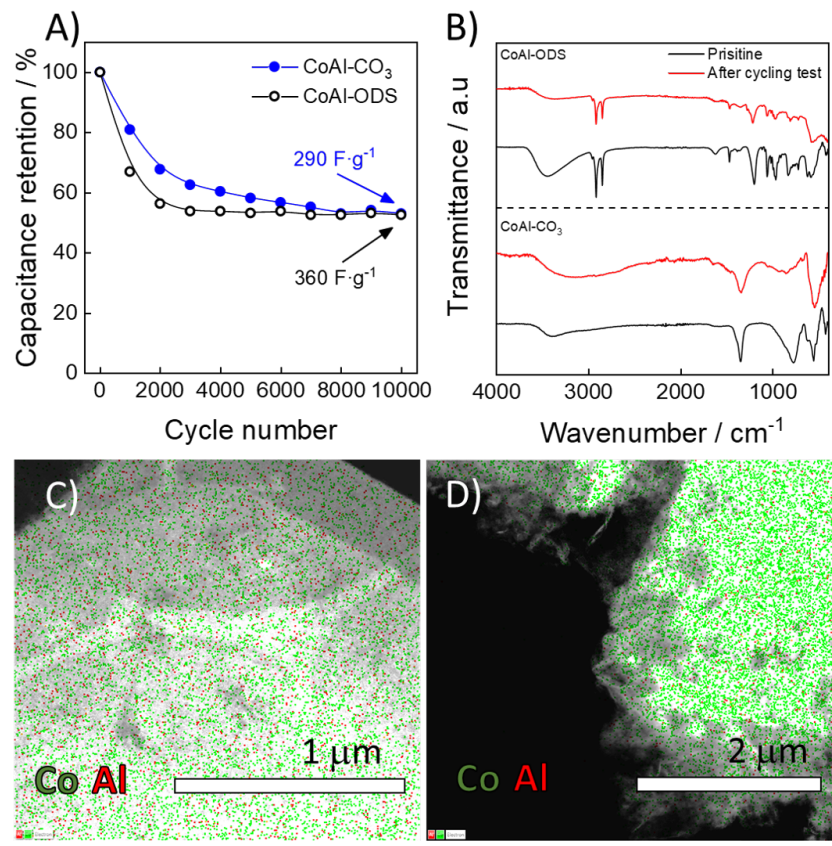

Figure 8. (A) Capacitance retention after 10000 charge and discharge cycles of $\mathrm{CoAl}(2: 1)-\mathrm{CO}_{3}$ and $\mathrm{CoAl}(2: 1)-\mathrm{ODS}$. (B) ATR-FTIR spectra of CoAI(2:1)$\mathrm{CO}_{3}$ and $\mathrm{CoAl}(2: 1)$-ODS before and after 10000 charge/discharge cycles. STEM mapping images of (C) $\mathrm{CoAl}(2: 1)-\mathrm{CO}_{3}$ and (D) $\mathrm{CoAl}(2: 1)-\mathrm{ODS}$ after 10000 charge/discharge cycles, highlighting the presence of Co (green dots) and $\mathrm{Al}$ (red dots) in the samples.

Taking into account that the positive charge coming from the hydroxide sheets is balanced by the interlayer anion, the excessive Al dissolution could involve the quick loss of interlayer anions, hence aggravating the capacitance retention. In this way, greater interlayer spacing should undergo faster Al dissolution and thus, superior interlayer anion loss. To study that, we characterized the samples after the cycling stability tests by means of ATR-FTIR and electron microscopy. The characteristic vibrational bands for both $-\mathrm{CO}_{3}$ and -ODS samples exhibit an intensity decrease after the charge/discharge cycles, indicative of a partial loss of the interlayer anion (Figure 8B), however ODS exhibits a remarkable resilience. Furthermore, the LDH phase was also conserved according to the $\mathrm{X}$-ray diffractograms after the charge/discharge cycles, as seen in Figure S19. The main basal reflections of both carbonate and octadecyl anion can be observed in their corresponding samples. In this context, the -ODS sample exhibits a shift towards lower 2-theta values depicting a basal space of ca. $41 \AA$, higher than the $32 \AA$ estimated for the pristine CoAl-ODS before the electrochemical process. As mentioned by Meyn et al., this fact is due to the arrangement of the surfactant anions into a bilayer disposition, and is the most suitable disposition for low amounts of interlayer surfactant mocules. ${ }^{[57]}$ As reported by these authors, for a carbon chain of 12 as in dodecyl sulfate anions, a basal spacing between ca. $23 \AA$ and $40 \AA$ can be observed for the single and bilayer orientation within the LDH layers, respectively. The loss of ODS molecules after the electrochemical process supports this hypothesis and therefore the basal space of ca. $41 \AA$ here reported. Also noteworthy is that large aliphatic chains like that of ODS prevents the intercalation of carbonate in the LDH phase, ${ }^{[54]}$ allowing the surfactant to remain after the cycling stability test and keeping the separation between layers (see Figure S20 for additional XRPD and FTIR experiments). In addition, transmission electron microscopy (TEM) images suggest an alteration on the surface of the LDH flakes in comparison with the pristine materials (Figure S21). This fact is related to the beforementioned Al dissolution after the cycling process. Furthermore, the CoAl(2:1)-ODS depicts even a more altered surface with respect to the $\mathrm{CoAl}(2: 1)-\mathrm{CO}_{3}$, as expected because of its larger basal spacing. In order to quantify the $\mathrm{Al}$ loss of the samples after the electrochemical characterization, a complete EDX mapping analysis was carried out in a scanning transmission electron microscope (STEM) operating at 200keV (Figure $8 \mathrm{C}, \mathrm{D}$ ). As stated in the mapping images, it is clearly pointed out a low quantity of Al throughout the whole sample (see Figure S22 for the individual element mapping). Furthermore, EDX quantification gives rise to a Co:Al ratio of $c a$. 4:1 and ca. 15:1 for the $\operatorname{CoAl}(2: 1)-\mathrm{CO}_{3}$ and $\operatorname{CoAl}(2: 1)-O D S$, respectively, indicative of an $\mathrm{Al}$ loss of $40 \%$ and $80 \%$ with respect to the original samples (see Figure S23 for the EDX histograms). Thus evidencing the Al removal from the structure and the higher accessibility at larger basal spaces. Hence, Al dissolution is responsible of an increment of the active sites exposed to the electrolyte but its dissolution is also influenced by the electrolyte accessibility revealing correlated processes that turn out to be transcendental for the electrochemical performance.

\section{Conclusions}

Herein, we have reported a family of CoAl-LDH obtained through anion exchange reactions with surfactant molecules in order to increase the interlayer space. These compounds exhibit similar size and dimension but different basal spaces to explore exclusively the impact of the interlayer distance in the supercapacitive performance. In this line, Co:Al ratios of 2:1, 3:1 and $4: 1$ were explored. An increase of the specific capacitance was observed in all cases when enlarging the basal space, reaching, in 2:1 ratio, almost $50 \%$ more than the value obtained 
from the pristine CoAl-LDH, up to ca. $750-1100 \mathrm{~F} \cdot \mathrm{g}^{-1}$ (measured at $1 \mathrm{~A} \cdot \mathrm{g}^{-1}$ ). This enhancement of ca. $260 \%$ mainly occurs because of the increase in the electrochemical surface area and of the associated higher electrolyte diffusion. Surprisingly, best performance is achieved for the lowest Co:Al ratio revealing the important role of the electrochemically inert $\mathrm{Al}$ in the structure. After the electrochemical characterization, some $\mathrm{Al}$ is removed with a partial loss of the interlayer anion. This is aggravated for the more spaced LDH likely due to the larger accessibility of the electrolyte. In this line, this work illustrates the importance of the accessible electroactive sites over the total amount of electroactive material, shedding light on the parameters governing the CoAl-LDHs supercapacitive performance.

\section{Experimental Section}

\section{Chemicals}

$\mathrm{CoCl}_{2} \cdot 6 \mathrm{H}_{2} \mathrm{O}, \mathrm{AlCl}_{3} \cdot 6 \mathrm{H}_{2} \mathrm{O}$, urea $\left(\mathrm{CH}_{4} \mathrm{~N}_{2} \mathrm{O}\right)$, sodium nitrate $\left(\mathrm{NaNO}_{3}\right)$, nitric acid $\left(\mathrm{HNO}_{3}\right)$, sodium sulfate $\left(\mathrm{Na}_{2} \mathrm{SO}_{4}\right)$, sodium octyl sulfate $\left(\mathrm{C}_{8} \mathrm{H}_{17} \mathrm{NaO}_{4} \mathrm{~S}\right)$, sodium dodecyl sulfate $\left(\mathrm{C}_{12} \mathrm{H}_{17} \mathrm{NaO}_{4} \mathrm{~S}\right)$, sodium octadecyl sulfate $\left(\mathrm{C}_{18} \mathrm{H}_{37} \mathrm{NaO}_{4} \mathrm{~S}\right)$, hexamethylenetetramine (HMT), acetylene black and polytetrafluoroethylene (PTFE) were purchased from Sigma-Aldrich. Sodium ethyl sulfate $\left(\mathrm{C}_{2} \mathrm{H}_{5} \mathrm{NaO}_{4} \mathrm{~S}\right)$ was purchased from TCl. Potassium hydroxide $\mathrm{KOH}(99.99 \%)$ and ethanol absolute $(\mathrm{EtOH})$ were purchased from Panreac. All chemicals were used as received. Milli- $Q$ water was obtained from a Millipore Milli- $Q$ equipment.

\section{Synthesis of LDHs}

$\mathrm{CoAl}(2: 1)-\mathrm{CO}_{3}$ and $\mathrm{CoAl}(3: 1)-\mathrm{CO}_{3}$

$\mathrm{CoAl}-\mathrm{CO}_{3} \mathrm{LDHs}$ with Co:Al ratio 2:1 and 3:1 were synthesized following the method described by Liu et al. ${ }^{[17]}$. In a typical procedure, the chloride salts of the metals $\left(\mathrm{CoCl}_{2} \cdot 6 \mathrm{H}_{2} \mathrm{O}\right.$ and $\left.\mathrm{AlCl}_{3} \cdot 6 \mathrm{H}_{2} \mathrm{O}\right)$ were dissolved in 500 $\mathrm{mL}$ of Milli-Q water together with urea $(0.07 \mathrm{M})$ in order to reach a total metal cation concentration of $0.03 \mathrm{M}$ with the corresponding stoichiometric ratio. Afterwards, the mixture was set under $\mathrm{Ar}$ atmosphere and magnetic stirring for $48 \mathrm{~h}$ at the refluxing temperature of $97^{\circ} \mathrm{C}$. Finally, it was cooled down to room temperature. Then, the final pink pale powder was filtered and washed with Milli-Q water and EtOH several times and dried during $24 \mathrm{~h}$ in vacuum at room temperature.

\section{$\mathrm{CoAl}(4: 1)-\mathrm{CO}_{3}$}

$\mathrm{CoAl}-\mathrm{CO}_{3} \mathrm{LDH}$ with Co:Al ratio 4:1 was synthesized with two different urea concentrations. The samples were obtained starting from solution with $0.012 \mathrm{M}$ of $\mathrm{CoCl}_{2} \cdot 6 \mathrm{H}_{2} \mathrm{O}, 0.003 \mathrm{M}$ of $\mathrm{AlCl}_{3} \cdot 6 \mathrm{H}_{2} \mathrm{O}$ and using different amounts of urea $(0.035$ and $0.105 \mathrm{M})$. The mixtures were set under $\mathrm{Ar}$ atmosphere and magnetic stirring at the temperature of $97^{\circ} \mathrm{C}$. The aging time was $48 \mathrm{~h}$ for both experiments. In all cases, the mixture was cooled down to room temperature. Then, the final pink pale powder was filtered and washed with Milli-Q water and $\mathrm{EtOH}$ several times and dried during $24 \mathrm{~h}$ in vacuum at room temperature. Only the sample synthesized with the higher urea quantity led to a $4: 1$ phase.
Brucite-like $\beta-\mathrm{Co}(\mathrm{OH})_{2}$ was synthesized following the method developed by Liu et al. ${ }^{[30]}$ Typically, $\mathrm{CoCl}_{2}(5 \mathrm{mM})$ and HMT $(60 \mathrm{mM})$ were dissolved in a 9:1 mixture of Milli-Q water and $\mathrm{EtOH}$. The reaction solution was heated at $90^{\circ} \mathrm{C}$ for $1 \mathrm{~h}$ under permanent magnetic stirring. After cooled down the reaction mixture to room temperature, the pink solid was isolated by filtration, washed several times with water and ethanol, and finally dried to the following characterization.

\section{Anion exchange reactions}

$\operatorname{CoAl}(2: 1)-\mathrm{NO}_{3}, \mathrm{CoAl}(3: 1)-\mathrm{NO}_{3}$ and $\mathrm{CoAl}(4: 1)-\mathrm{NO}_{3}$

CoAl-NO $\mathrm{NDH}_{3}$ with Co:Al ratio 2:1, 3:1 and 4:1 were obtained dissolving in $1 \mathrm{~L}$ of degassed Milli-Q water $1.5 \mathrm{M}$ of sodium nitrate and 5,4 and 3 $\mathrm{mM}$ of nitric acid respectively. Then, $1 \mathrm{~g}$ of $\mathrm{CoAl}-\mathrm{CO}_{3} \mathrm{LDH}$ were added and the reaction was maintained for $96 \mathrm{~h}$ at room temperature under $\mathrm{Ar}$ atmosphere and magnetic stirring. Finally, the mixture was filtered, washed with Milli-Q water and $\mathrm{EtOH}$, and the final product was dried in vacuum at room temperature.

$\mathrm{CoAl}(2: 1)-\mathrm{SO}_{4}$ and $\mathrm{CoAl}(3: 1)-\mathrm{SO}_{4}$

$0.25 \mathrm{M}$ of sodium sulfate was dissolved in $50 \mathrm{~mL}$ of a $1: 1$ (v:v) ethanol:water with magnetic stirring at $65{ }^{\circ} \mathrm{C}$. Then, $50 \mathrm{mg}$ of $\mathrm{CoAl}-\mathrm{NO}_{3}$ were added and the reaction was kept for $48 \mathrm{~h}$ at $50{ }^{\circ} \mathrm{C}$ under $\mathrm{Ar}$ atmosphere and magnetic stirring. The resulting mixture was filtered, washed with Milli-Q water and $\mathrm{EtOH}$, and the final product was dried in vacuum at room temperature.

\section{CoAl(2:1)-ES, CoAl(2:1)-OS, CoAl(3:1)-ES and CoAl(3:1)-OS}

$0.015 \mathrm{M}$ of sodium ethyl sulfate or sodium octyl sulfate (SES or SOS) was dissolved in $50 \mathrm{~mL}$ of a 1:1 (v:v) ethanol:water with magnetic stirring at room temperature. Then, $50 \mathrm{mg}$ of $\mathrm{CoAl}-\mathrm{NO}_{3} \mathrm{LDH}$ were added, respectively, and the reaction was maintained for $48 \mathrm{~h}$ at room temperature under $\mathrm{Ar}$ atmosphere and magnetic stirring. The resulting mixture was filtered, washed with Milli-Q water and $\mathrm{EtOH}$, and the final product was dried in vacuum at room temperature.

\section{CoAl(2:1)-DS and CoAI(3:1)-DS}

$0.2 \mathrm{M}$ of sodium dodecyl sulfate was dissolved in $50 \mathrm{~mL}$ of a 1:1 (v:v) ethanol:water mixture with magnetic stirring at room temperature. Then, $200 \mathrm{mg}$ of $\mathrm{CoAl}-\mathrm{NO}_{3}$ were added, respectively, and the reaction was maintained for $12 \mathrm{~h}$ at room temperature under $\mathrm{Ar}$ atmosphere and magnetic stirring. Finally, each mixture was filtered, washed with Milli- $Q$ water and $\mathrm{EtOH}$, and the final product was dried in vacuum at room temperature.

\section{CoAl(2:1)-ODS, CoAl(3:1)-ODS and CoAl(4:1)-ODS}

$0.01 \mathrm{M}$ of sodium octadecyl sulfate was dissolved in $50 \mathrm{~mL}$ of a 1:1 (v:v) ethanol:water mixture with magnetic stirring at room temperature. Then, $50 \mathrm{mg}$ of $\mathrm{CoAl}-\mathrm{NO}_{3} \mathrm{LDH}$ were added and the reaction was maintained for $12 \mathrm{~h}$ at room temperature under $\mathrm{Ar}$ atmosphere and magnetic stirring. Finally, the mixture was filtered, washed with Milli-Q water and $\mathrm{EtOH}$, and the final product was dried in vacuum at room temperature.

\section{Synthesis of $\beta-\mathrm{Co}(\mathrm{OH})_{2}$}


The $\mathrm{CoAl}(2: 1)-\mathrm{NO}_{3}$ was exfoliated following the method described by $\mathrm{Hu}$ et al. ${ }^{[69]}$ In a typical procedure, $0.5 \mathrm{~g} \cdot \mathrm{L}^{-1}$ of $\mathrm{CoAl}(2: 1)-\mathrm{NO}_{3}$ were dispersed in $100 \mathrm{ml}$ of degassed formamide and sonicated for $10 \mathrm{~min}$ and then mechanically stirred under $\mathrm{N}_{2}$ atmosphere for $24 \mathrm{~h}$. A yellow translucent colloidal suspension was formed and kept in a refrigerator at $4{ }^{\circ} \mathrm{C}$.

\section{Structural Characterization}

X-ray powder diffraction (XRPD) patterns were obtained with a PANalytical Empyrean X-ray platform using a capillary platform and copper radiation $\left(\mathrm{Cu} \mathrm{Ka}=1.54178 \AA\right.$ ) in the $2-70^{\circ}$ region. Attenuated total reflectance-Fourier transform infrared spectroscopy (ATR-FTIR) spectra were collected in a Bruker alpha II FTIR spectrometer in the $4000-400 \mathrm{~cm}^{-1}$ range in absence of $\mathrm{KBr}$ pellets. UV/Vis absorption spectra of the solid samples were recorded in a reflectance mode using an Jasco V-670 spectrometer. Field emission scanning electron microscopy (FESEM) and energy dispersive X-ray (EDX) spectroscopy mappings studies were performed on a Hitachi S-4800 microscope at an accelerating voltage of $20 \mathrm{kV}$ and $30 \mathrm{~s}$ of $\mathrm{Au} / \mathrm{Pd}$ metallization of the samples. Transmission electron microscopy (TEM) was performed on a JEM-1010 operating at $80 \mathrm{kV}$. Samples were prepared by dropping suspensions on lacey Formvar/carbon copper grids (300 mesh). For the characterization of the sample after the electrochemical treatment, EDS X-Max 80 from Oxford Instruments coupled with the JEM-1010 in scanning transmission electron microscopy (STEM) mode was used to carry out the EDX and mapping analysis. Thermogravimetric analysis (TGA) of all samples was performed on a Mettler Toledo TGA/DSC2 apparatus in the $30-800{ }^{\circ} \mathrm{C}$ temperature range at $10^{\circ} \mathrm{C} \cdot \mathrm{min}^{-1}$ scan rate and an airflow of $100 \mathrm{~mL} \cdot \mathrm{min}^{-1}$. Carbon, nitrogen, hydrogen, and sulphur contents were determined by microanalytical procedures by using an LECO CHNS-932. X-ray photoelectron spectroscopy (XPS) measurements were performed in an ultrahigh vacuum system ESCALAB210 (base pressure $1.0 \times 10^{-10} \mathrm{mbar}$ ) from Thermo VG Scientific. Photoelectrons were excited by using the Al Ka line (1486.6 eV). All spectra were referred to the Fermi level. Magnetic data were collected over the bulk material with a Quantum Design superconducting quantum interference device (SQUID) MPMS-XL-5. The magnetic susceptibility of the samples was corrected considering the diamagnetic contributions of their atomic constituents as deduced from Pascal's constant tables and the sample holder. The dc data were recorded under an external applied field of 100 or $1000 \mathrm{Oe}$ in the $2-300 \mathrm{~K}$ temperature range. The ac data were collected under an applied field of $3.95 \mathrm{Oe}$ at $997,333,110,10$, and $1 \mathrm{~Hz}$.

\section{Electrode Preparation}

For the electrochemical measurements, a mixture of the LDH, acetylene black and PTFE in ethanol in a mass ratio of $80: 10: 10$ was prepared and deposited on a nickel foam electrode. The as-prepared electrode was let dry for $2 \mathrm{~h}$ at $80{ }^{\circ} \mathrm{C}$. Each working electrode contained about $0.5 \mathrm{mg}$ of metal hydroxides (i.e. $\mathrm{Co}_{1-\chi} \mathrm{Al}_{\chi}(\mathrm{OH})_{2}$ ) and a geometric surface area of about $2 \mathrm{~cm}^{2}$. Additionally, an electrode with a higher content of acetylene black $(70 \%)$ was tested to ensure that the percolation limit is not significantly affecting the $\mathrm{CV}$ shape (Figure S24). ${ }^{71]}$ A typical threeelectrode cell equipped with a steel sheet as the counter electrode and a Metrohm $\mathrm{Ag} / \mathrm{AgCl}(3 \mathrm{M} \mathrm{KCl})$ as the reference electrode was used for the electrochemical characterization of the nanocomposite materials.

\section{Electrochemical Characterization}

The electrochemical measurements were carried out in $6 \mathrm{M} \mathrm{KOH}$ $(99.99 \%)$ aqueous solutions as the electrolyte. All the electrochemical experiments were performed at room temperature using a
Potentiostat/Galvanostat Autolab $128 \mathrm{~N}$ controlled by Nova 2.1 electrochemical software, and a Gamrylnterface 1000E potentiostatgalvanostat controlled by Gamry's Global Software. Cyclic voltammetry curves (CVs) were carried out between $-0.1-0.4 \mathrm{~V}$ versus $\mathrm{Ag} / \mathrm{AgCl}$ at different scan rates $\left(100,50,20,10\right.$ and $\left.5 \mathrm{mV} \cdot \mathrm{s}^{-1}\right)$. Charge/discharge curves were performed between $-0.1-0.4 \mathrm{~V}$ versus $\mathrm{Ag} / \mathrm{AgCl}$ at different current density $\left(30,20,10,5,2\right.$ and $\left.1 \mathrm{~A} \cdot \mathrm{g}^{-1}\right)$. The measurements were performed at least three times for every sample using different electrodes. The specific capacitance (C) was calculated from the discharge curves according to the following equation:

$$
\mathrm{C}=\frac{\mathrm{I} \cdot \Delta \mathrm{t}}{\mathrm{m} \cdot \Delta \mathrm{V}}
$$

Where I is the discharge current, $\Delta \mathrm{t}$ is the time for a full discharge, $\mathrm{m}$ the weight in grams of the active material in the electrode layer, and $\Delta \mathrm{V}$ is the voltage change after a full discharge.

Capacity retention was evaluated during 10000 charge/discharge cycles at a constant current density of $20 \mathrm{~A} \cdot \mathrm{g}^{-1}$ for the $\mathrm{CoAl}(2: 1)-\mathrm{CO}_{3}$ and CoAl(2:1)-ODS samples.

Electrochemical surface area was acquired by measuring the current associated with double-layer capacitance from the scan rate dependence of CVs. The ECSA was measured on the working electrodes after cyclic voltammetry curves. The potential range used for the CVs was from - 0.3 to $-0.1 \mathrm{~V}$ versus $\mathrm{Ag} / \mathrm{AgCl}(3 \mathrm{M} \mathrm{KCl})$. The scan rates were 200, 100, 50, 20 and $10 \mathrm{mV} \mathrm{s}^{-1}$. The double-layer capacitance was calculated by plotting the (ja-jc) (anodic versus cathodic currents) at $-0.2 \mathrm{~V}$ versus $\mathrm{Ag} / \mathrm{AgCl}(3 \mathrm{M} \mathrm{KCl})$ against the scan rate. ECSA measurements were obtained in an Autolab PGSTAT $128 \mathrm{~N}$ potentiostat/galvanostat.

Electrochemical impedance spectroscopy (EIS) measurements were carried out by applying an AC amplitude of $10 \mathrm{mV}$ in the frequency range of $0.01-10^{4} \mathrm{~Hz}$ at the open circuit potential. EIS data were analysed and fitted by means of Gamry Echem Analyst v. 7.07 software.

\section{Acknowledgements}

This work was partially supported by the European Research Council (ERC; Grant No. Mol-2D 788222 to E.C. and ERC Grant No. 2D-PnictoChem 804110 to G.A.). G.A. thanks the Generalitat Valenciana (SEJI/2018/034 Grant and CIDEGENT/2018/001). R.S.-G. thanks the Ministerio de Ciencia, Innovación y Universidades, for the F.P.U. fellowship. This work was supported by the Spanish MINECO (Unit of Excellence "Maria de Maeztu" MDM-2015-0538 and Project No. MAT201789993-R cofinanced by FEDER) and Generalitat Valenciana (Prometeo/2017/066). Authors thank Dr. Anna Nowacka and Dr. Antonio Leyva from ITQ-UPV for STEM studies, and Dr. María Dolores Jordán for her assistance with the XPS measurements.

Keywords: Layered double hydroxide, interlayer space, supercapacitors, energy storage.

[1] H. Lund, Energy 2007, 32, 912-919.

[2] P. J. Hall, E. J. Bain, Energy Policy 2008, 36, 4352-4355.

[3] I. Hadjipaschalis, A. Poullikkas, V. Efthimiou, Renew. Sustain. Energy Rev. 2009, 13, 1513-1522.

[4] K. S. Kumar, N. Choudhary, Y. Jung, J. Thomas, ACS Energy Lett. 2018, 3, 482-495. 
[5] Y. Liu, X. Peng, Appl. Mater. Today 2017, 8, 104-115.

[6] X. Li, D. Du, Y. Zhang, W. Xing, Q. Xue, Z. Yan, J. Mater. Chem. A 2017, 5, 15460-15485.

[7] H. Chen, L. Hu, M. Chen, Y. Yan, L. Wu, Adv. Funct. Mater. 2014, 24, 934-942.

[8] Q. Wang, D. O'Hare, Chem. Rev. 2012, 112, 4124-4155.

[9] L. Hou, Q. Du, L. Su, S. Di, Z. Ma, L. Chen, G. Shao, Mater Lett. 2019, 237, 262-265.

[10] W. Wang, N. Zhang, Z. Ye, Z. Hong, M. Zhi, Inorg. Chem. Front. 2019, 6, 407-416.

[11] G. Abellán, J. A. Carrasco, E. Coronado, in Layer. Double Hydroxide Polym. Nanocomposites, Elsevier, 2020, pp. 411-460.

[12] X. Wu, L. Jiang, C. Long, T. Wei, Z. Fan, Adv. Funct. Mater. 2015, 25, 1648-1655.

[13] L. Wang, Z. H. Dong, Z. G. Wang, F. X. Zhang, J. Jin, Adv. Funct. Mater. 2013, 23, 2758-2764.

[14] J. A. Carrasco, R. Sanchis-Gual, A. Seijas-Da Silva, G. Abellán, E. Coronado, Chem. Mater. 2019, 31, 6798-6807.

[15] Y. Dong, S. Komarneni, F. Zhang, N. Wang, M. Terrones, W. Hu, W. Huang, Appl. Catal. B Environ. 2019, 118343.

[16] B. M. Hunter, W. Hieringer, J. R. Winkler, H. B. Gray, A. M. Müller, Energy Environ. Sci. 2016, 9, 1734-1743.

[17] Z. Liu, R. Ma, M. Osada, N. Iyi, Y. Ebina, K. Takada, T. Sasaki, J. Am. Chem. Soc. 2006, 128, 4872-4880.

[18] J. A. Carrasco, S. Cardona-Serra, J. M. Clemente-Juan, A. Gaita-Ariño, G. Abellán, E. Coronado, Inorg. Chem. 2018, 57, 2013-2022.

[19] G. Abellán, J. L. Jordá, P. Atienzar, M. Varela, M. Jaafar, J. Gómez-Herrero, F. Zamora, A. Ribera, H. García, E. Coronado, Chem Sci 2015, 6, 1949-1958.

[20] D. Li, Y. Ding, X. Wei, Y. Xiao, L. Jiang, Appl. Catal. Gen. 2015, 507, 130-138.

[21] J.-Y. Lee, G.-H. Gwak, H.-M. Kim, T. Kim, G. J. Lee, J.-M. Oh, Appl. Clay Sci. 2016, 134, 44-49.

[22] M. del Arco, S. Gutiérrez, C. Martín, V. Rives, J. Rocha, J. Solid State Chem. 2000, 151, 272-280.

[23] J.-B. d'Espinose de la Caillerie, M. Kermarec, O. Clause, J. Am. Chem. Soc. 1995, 117, 11471-11481.

[24] I. G. Richardson, Acta Crystallogr. Sect. B Struct. Sci. Cryst. Eng. Mater. 2013, 69, 150-162.

[25] M. Kaneyoshi, W. Jones, J. Mater. Chem. 1999, 9, 805811.

[26] I. G. Richardson, Acta Crystallogr. Sect. B Struct. Sci. Cryst. Eng. Mater. 2013, 69, 414-417.

[27] N. Iyi, K. Fujii, K. Okamoto, T. Sasaki, Appl. Clay Sci. 2007. 35, 218-227

[28] G. Yang, T. Takei, S. Yanagida, N. Kumada, Mol. Basel Switz. 2019, 24, 976.

[29] P. Guoxiang, X. Xinhui, L. Jingshan, C. Feng, Y. Zhihong, F. Hongjin, Appl. Clay Sci. 2014, 102, 28-32.

[30] Z. Liu, R. Ma, M. Osada, K. Takada, T. Sasaki, J. Am. Chem. Soc. 2005, 127, 13869-13874.

[31] L. Zhu, S. Pu, F. Lu, K. Liu, T. Zhu, J. Li, J. Li, Mater. Chem. Phys. 2012, 135, 979-984.

[32] J. T. Kloprogge, H. D. Ruan, R. L. Frost, J. Mater. Sci. 2002, 37, 1121-1129.

[33] P. H. Hsu, T. F. Bates, Mineral. Mag. J. Mineral. Soc. 1964, 33, 749-768.

[34] S. J. Duffy, G. W. vanLoon, Environ. Sci. Technol. 1994, 28, 1950-1956.

[35] R. Xu, S. Xiao, J. Jiang, Y. Wang, J. Chem. Eng. Data 2011, 56, 2536-2542.

[36] J. Zhang, X. Xie, C. Li, H. Wang, L. Wang, RSC Adv 2015, 5, 29757-29765.
[37] T. Xiao, Y. Tang, Z. Jia, D. Li, X. Hu, B. Li, L. Luo, Nanotechnology 2009, 20, 475603.

[38] J. A. Carrasco, J. Romero, M. Varela, F. Hauke, G. Abellán, A. Hirsch, E. Coronado, Inorg Chem Front 2016, 3, 478487.

[39] F. L. Theiss, G. A. Ayoko, R. L. Frost, J. Therm. Anal. Calorim. 2013, 112, 649-657.

[40] V. Oestreicher, M. Jobbágy, Chem. - Eur. J. 2019, 25, 12611-12619.

[41] R. Ma, Z. Liu, K. Takada, K. Fukuda, Y. Ebina, Y. Bando, T. Sasaki, Inorg. Chem. 2006, 45, 3964-3969.

[42] V. Oestreicher, I. Fábregas, M. Jobbágy, J. Phys. Chem. C 2014, 118, 30274-30281.

[43] Z. Tian, Q. Li, J. Hou, L. Pei, Y. Li, S. Ai, J. Catal. 2015, 331, 193-202.

[44] Y. Qiu, B. Lin, F. Jia, Y. Chen, B. Gao, P. Liu, Mater. Res. Bull. 2015, 72, 235-240.

[45] P. T. Babar, A. C. Lokhande, B. S. Pawar, M. G. Gang, E. Jo, C. Go, M. P. Suryawanshi, S. M. Pawar, J. H. Kim, Appl. Surf. Sci. 2018, 427, 253-259.

[46] M. Jana, P. Sivakumar, M. Kota, M. G. Jung, H. S. Park, J. Power Sources 2019, 422, 9-17.

[47] G. Abellán, C. Martí-Gastaldo, A. Ribera, E. Coronado, Acc. Chem. Res. 2015, 48, 1601-1611.

[48] M. del Arco, R. Trujillano, V. Rives, J. Mater. Chem. 1998, 8, 761-767.

[49] G. Abellán, J. A. Carrasco, E. Coronado, Inorg. Chem. 2013, 52, 7828-7830.

[50] M. Kurmoo, Chem. Mater. 1999, 11, 3370-3378.

[51] H. B. Li, P. Liu, Y. Liang, J. Xiao, G. W. Yang, RSC Adv. 2013, 3, 26412.

[52] A. Gupta, S. D. Tiwari, Phys. B Condens. Matter 2017, 525, 21-25.

[53] Z. Wang, M. S. Seehra, J. Phys. Condens. Matter 2017, 29, 225803.

[54] L. Dang, H. Liang, J. Zhuo, B. K. Lamb, H. Sheng, Y. Yang, S. Jin, Chem. Mater. 2018, 30, 4321-4330.

[55] M. Meyn, K. Beneke, G. Lagaly, Inorg. Chem. 1990, 29 , 5201-5207.

[56] S. V. Prasanna, P. V. Kamath, Ind. Eng. Chem. Res. 2009, 48, 6315-6320.

[57] M. Meyn, K. Beneke, G. Lagaly, Inorg. Chem. 1993, 32, 1209-1215.

[58] A. A. Ansari, M. Kamil, Kabir-ud-Din, J. Dispers. Sci. Technol. 2013, 34, 722-730.

[59] R. B. Viana, A. B. F. da Silva, A. S. Pimentel, Adv. Phys. Chem. 2012, 2012, 1-14.

[60] Y. Liu, Z. Yang, RSC Adv. 2016, 6, 68584-68591.

[61] J. P. Cheng, J. Zhang, F. Liu, RSC Adv 2014, 4, 3889338917.

[62] P. Simon, Y. Gogotsi, Nat. Mater. 2008, 7, 845-854.

[63] T. M. Masikhwa, M. J. Madito, D. Y. Momodu, J. K. Dangbegnon, O. Guellati, A. Harat, M. Guerioune, F. Barzegar, N. Manyala, RSC Adv. 2016, 6, 46723-46732.

[64] W. Peng, H. Li, S. Song, ACS Appl. Mater. Interfaces 2017 9, 5204-5212.

[65] X. Wang, Y. Lin, Y. Su, B. Zhang, C. Li, H. Wang, L. Wang, Electrochimica Acta 2017, 225, 263-271.

[66] Y. Wang, W. Yang, C. Chen, D. G. Evans, J. Power Sources 2008, 184, 682-690.

[67] X. Gao, X. Liu, D. Wu, B. Qian, Z. Kou, Z. Pan, Y. Pang, L. Miao, J. Wang, Adv. Funct. Mater. 2019, 1903879.

[68] Z. Feng, Z. Yang, B. Yang, Z. Zhang, X. Xie, J. Power Sources 2014, 266, 22-28.

[69] F. Song, X. Hu, Nat. Commun. 2014, 5, 1-9. 
[70] J. A. Carrasco, A. Harvey, D. Hanlon, V. Lloret, D. McAteer, R. Sanchis-Gual, A. Hirsch, F. Hauke, G. Abellán, J. N. Coleman, et al., Chem. Commun. 2019, 55, 3315-3318.
[71] D. McAteer, I. J. Godwin, Z. Ling, A. Harvey, L. He, C. S. Boland, V. Vega-Mayoral, B. Szydłowska, A. A. Rovetta, C. Backes, et al., Adv. Energy Mater. 2018, 8, 1702965. 
